\title{
Expression level of vascular endothelial growth factor-C and -A in cultured human oral squamous cell carcinoma correlates respectively with lymphatic metastasis and angiogenesis when transplanted into nude mouse oral cavity
}

\author{
TAKAYUKI NAKAZATO ${ }^{1}$, SUSUMU SHINGAKI ${ }^{1}$, NOBUTAKA KITAMURA ${ }^{2}$, \\ CHIKARA SAITO $^{1}$, RYOZO KUWANO $^{3}$ and MASAYOSHI TACHIBANA ${ }^{3}$
}

\begin{abstract}
${ }^{1}$ Division of Reconstructive Surgery for Oral and Maxillofacial Region, Niigata University Graduate School of Medical and Dental Sciences, 2-5274 Gakkocho, Niigata 951-8514; ${ }^{2}$ Division of Information Science and Biostatistics, Niigata University Graduate School of Medical and Dental Sciences; ${ }^{3}$ Genome Science Branch, Center for Bioresource-based Researches, Brain Research Institute, Niigata University, 1-757, Asahimachi, Niigata 951-8510, Japan
\end{abstract}

Received September 16, 2005; Accepted November 14, 2005

\begin{abstract}
Angiogenesis is induced by various angiogenic factors including vascular endothelial growth factors (VEGFs), such as VEGF-A, -B, -C and -D, and is involved in tumor progression and metastasis. In an effort to define the expression pattern of VEGFs in oral squamous cell carcinoma (OSCC) and its correlation with clinicopathological factors, we determined the expression levels of VEGFs in OSCC cell lines (HSC-2, HSC-3, HSC-4 and OSC-19) by quantitative RT-PCR and examined their relationship with regional lymph node (LN) and distant metastasis, intratumoral microvessel density (MVD) in tumor transplanted nude mice. We found that HSC-2 and OSC-19 expressed significantly higher levels of VEGF-A and VEGF-C, and caused frequent regional LN metastasis and higher MVD than did the other cell lines. Since VEGF-C is a lymphangiogenic factor, these results suggest that expression of VEGF-C is a useful predictor for LN metastasis.
\end{abstract}

\section{Introduction}

Angiogenesis is one of the important factors that determine the growth and metastasis of solid tumors. While angiogenesis is regulated by a number of angiogenic factors, it has been suggested that vascular endothelial growth factors (VEGFs) play an important role in tumor angiogenesis (1). After the discovery of VEGF-A, three other members of VEGFs, i.e. VEGF-B, -C and -D were discovered and characterized (2-6).

Correspondence to: Dr Takayuki Nakazato, Division of Reconstructive Surgery for Oral and Maxillofacial Region, Niigata University Graduate School of Medical and Dental Sciences, 2-5274, Gakkocho, Niigata 951-8514, Japan

E-mail: nakazato@dent.niigata-u.ac.jp

Key words: vascular endothelial growth factor, lymph node metastasis, ural squamous cell carcinoma
VEGFs are expressed in a variety of human tumors including breast cancer, head and neck squamous cell carcinoma (HNSCC) and oral squamous cell carcinoma (OSCC) (7-9), and it was previously shown that expression of VEGF-A plays an important role in tumor angiogenesis and blood-borne metastasis (10). In addition, recent studies have demonstrated that VEGF-A is a reliable prognostic factor for HNSCC and OSCC (11-14). While VEGF-C stimulates the migration and proliferation of vascular endothelial cells, its ability to stimulate angiogenesis is lower than that of VEGF-A $(15,16)$. On the other hand, VEGF-C is now known to be a lymphangiogenic factor that stimulates lymphatic proliferation (17). In harmony with these data, recent studies have revealed that VEGF-C probably promotes the spread of cancer cells through lymphatic channels (18-20). VEGF-B, which also affects angiogenesis, is thought to play a role in endothelial cell migration and matrix remodeling, where it regulates the urokinase plasminogen activator (uPA) and its inhibitor, plasminogen activator inhibitor-1 (PAI-1) (21). The role of VEGF-D is to stimulate both endothelial and lymphatic cells, and it has also been found to promote the metastatic spread of cancer cells via the lymphatic system (22). Although the expression of the VEGFs in OSCC has been extensively studied, the precise expression pattern of VEGFs is still unclear, as is the question of whether the expression pattern of VEGFs in each OSCC is related to clinicopathological factors. In an effort to define the expression pattern of VEGFs in OSCC, we identified the expression levels of VEGF-A, -B, -C and -D in OSCC cell lines. Then we investigated their relationship to lymph node (LN) metastasis, distant metastasis, and intratumoral microvessel density (MVD) in tumor transplanted nude mice.

\section{Materials and methods}

Cell lines and culture. OSCC cell lines HSC-2, -3, -4 (23) were obtained from Cell Resource Center for Biomedical Research in Tohoku University (Sendai, Japan), and OSC-19 (24) was 
Table I. Primer sequences for VEGFs and SCCA used for RT-PCR.

\begin{tabular}{llc}
\hline Primer & \multicolumn{1}{c}{ Sequence $\left(5^{\prime}-3^{\prime}\right)$} & Expected product size (bp) \\
\hline VEGF-A & & 220 \\
Sense & AAGGAGGAGGGCAGAATCAT & 164 \\
Anti-sense & TGGTGATGTTGGACTCCTCA & \\
VEGF-B & & 292 \\
Sense & CTGTGGAGCTCATGGGCACC & \\
Anti-sense & CAGCTGACTGCTCGGGTACC & 387 \\
VEGF-C & & \\
Sense & & \\
Anti-sense & GGAGGCTGGCAACATAACAG & \\
VEGF-D & ACGTCTTGCTGAGGTAGCTC & \\
Sense & & \\
Anti-sense & AGCGATCATCTCAGTCCACA & \\
SCCA & AGGTGCTGGTGTTCATACAG & \\
Outer sense & & \\
Outer anti-sense & GAGTTCCAGATCACATCG & \\
SCCA & CTTCTGGAGCATTTGCA & \\
Inner sense & TCAGTGAAGCCAACACCAAG & \\
Inner anti-sense & & \\
\hline
\end{tabular}

kindly provided by Professor E.Yamamoto (Department of Oral and Maxillofacial Surgery, Kanazawa University, Japan). The cells were harvested in 100-mm plastic dishes and cultured in Dulbecco's modified Eagle's medium supplemented with $10 \%$ fetal bovine serum and antibiotics, until they reached subconfluence. Normal oral epithelial cells were used as controls. These cells were established using normal oral mucosae from patients who were undergoing dental extractions, preprosthetic surgeries, or gingivectomy, with informed consent. Cells were cultured until they reached subconfluence according to a previous study (25).

Tumor transplantation. The protocol for the following tumor transplantation studies was approved by the Ethics Committee of Niigata University. Sixty-one athymic BALB/c-nu/nu nude mice (CLEA Japan, Tokyo, Japan) were used at 5 weeks of age. They were maintained in a plastic isolator under specific pathogen-free conditions. Four OSCC cell lines, HSC-2 $(n=14)$, $-3(n=14),-4(n=16)$, and OSC-19 $(n=15)$, were injected into mouse tongue via an intra-oral approach at $2.0 \times 10^{5}$ viable cells/ $0.025 \mathrm{ml}$ in cell culture medium per mouse, using a microliter syringe (Hamilton, Nevada, USA) with a 26-gauge disposable needle (Terumo, Tokyo, Japan). As controls, two mice were not injected with tumor cells. All mice were sacrificed on day 21 post implantation, and submitted for autopsy. At autopsy, oral tumors, cervical LN and lung were removed using an operating microscope (SZ40, Olympus, Tokyo, Japan).

Quantitative RT-PCR. Total RNA of cultured cells (HSC-2, $\mathrm{n}=7$; HSC $-3, \mathrm{n}=7$; HSC $-4, \mathrm{n}=6$; OSC -19 , $\mathrm{n}=6$; Normal epithelial cells, $n=6$ ) was isolated by ISOGEN (Nippon Gene, Tokyo, Japan) and used for the synthesis of first-strand
cDNA using reverse transcriptase (Superscript II, Invitrogen, CA, USA) and random hexamers (Invitrogen). The RT product was amplified by PCR with Taq DNA polymerase (Takara EX Taq R-PCR version, Takara, Shiga, Japan) and specific primers as shown in Table I. These primer sets for the detection of VEGF mRNA were designed to span introns, the PCR products were cloned into the PCR2.1 vector using the TA cloning system (Invitrogen). These plasmids were grown in Escherichia coli TOP10 and prepared by cecium chloride density-gradient centrifugation for use as the external standard. To determine the levels of VEGF mRNA in OSCC cell lines and normal oral epithelial cells, we performed quantitative realtime PCR analysis using Smart cycler (Cepheid, CA, USA). The following PCR protocol was applied: after $30 \mathrm{sec}$ at $95^{\circ} \mathrm{C}$, each of 40 cycles had $15 \mathrm{sec}$ at $95^{\circ} \mathrm{C}$ followed by $30 \mathrm{sec}$ at $68^{\circ} \mathrm{C}$ for extension. Real-time monitoring of PCR products was done using fluorescence of SYBR green I (Takara). Standard curve for VEGF plasmids were created, and the level of VEGFs were expressed as the number of target molecules/ $1 \mu \mathrm{g}$ RNA. We confirmed the RT-PCR products by $3 \%$ agarose gel electrophoresis.

Immunohistochemistry. Oral tumors were fixed with $4 \%$ paraformaldehyde, embedded in paraffin, and cut into $4 \mu \mathrm{m}$ thick sections. Tissue sections were deparaffinized and immersed in methanol with $0.3 \%$ hydrogen peroxide. After treatment with $5 \%$ skimmed milk for $30 \mathrm{~min}$, the sections were incubated with primary antibody at $4{ }^{\circ} \mathrm{C}$ overnight. For detection of blood microvessels, we used a monoclonal rat anti-mouse CD34 antibody (Hycult Biotechnology, Uden, The Netherlands) (diluted at 1:200) that is commonly used for determing MVD by staining endothelial cells of blood vessels. 
Table II. The expession of VEGFs at mRNA levels in OSCC cell lines.

\begin{tabular}{lcrrrr}
\hline OSCC cell lines & & VEGF-A & VEGF-B & VEGF-C & VEGF-D \\
\hline HSC-2 $(\mathrm{n}=7)$ & Mean & 15276.074 & 3027.153 & 18216.515 & 2.251 \\
& $\mathrm{SD}$ & 3061.183 & 892.403 & 4010.157 & 2.528 \\
HSC-3 $(\mathrm{n}=7)$ & $\mathrm{Mean}$ & 6809.566 & 3240.827 & 8972.123 & 16.112 \\
& $\mathrm{SD}$ & 3744.434 & 1050.986 & 3802.098 & 9.287 \\
HSC-4 $(\mathrm{n}=6)$ & $\mathrm{Mean}$ & 8125.705 & 3835.441 & 11093.447 & 21.857 \\
& $\mathrm{SD}$ & 2753.539 & 2210.947 & 12701.276 & 10.921 \\
OSC-19 $(\mathrm{n}=6)$ & $\mathrm{Mean}$ & 11956.277 & 5837.171 & 20461.623 & 11.959 \\
& $\mathrm{SD}$ & 5718.487 & 3235.023 & 2823.833 & 9.719 \\
Normal $(\mathrm{n}=6)$ & $\mathrm{Mean}$ & 5340.380 & 273.056 & 5827.416 & 4.388 \\
& $\mathrm{SD}$ & 2752.635 & 153.912 & 7046.738 & 5.233 \\
\hline
\end{tabular}

The standard streptavidin-biotin-peroxidase complex method was used to bind the primary antibody with the use of a Histomark Streptavidin-HRP system (Kirkegaad \& Perry Laboratories, MD, USA). Reaction products were visualized by $0.02 \%$ diaminobenzidine solution containing $0.05 \%$ hydrogen peroxide. Sections were then counterstained with hematoxylin.

Assessment of microvessel density. The three most hypervascular areas (hot spots) were selected under microscopic observation at low magnification (x50) for MVD assessment. These areas were then observed at high magnification (x200) and the number of vessels per field was counted. Any single endothelial cell was counted as a single microvessel. The mean values for the three fields were recorded as the MVD for each tumor.

Detection of lymph node metastasis. To detect LN metastasis, we examined the expression of squamous cell carcinoma antigen (SCCA) mRNA in cervical LN by RT-nested PCR. SCCA is a tumor-associated antigen and a serological marker for squamous cell carcinomas in a number of organs (26-28). The usefulness of molecular diagnosis of micrometastasis by RT-PCR based on SCCA mRNA expression has been reported (29-31). LN of tumor transplanted mice were placed in ISOGEN and immediately homogenized. Total RNA was isolated by ISOGEN and used for the synthesis of first-strand cDNA as described above. As controls, tongue and $\mathrm{LN}$ of mice without tumor transplanted and four OSCC cell lines (HSC-2, HSC-3, HSC-4, OSC-19) were used. To confirm the sensitivity of this RT-nested PCR assay, a 10-fold dilution series of $1 \times 10^{6}$ to $1 \times 10^{0}$ cultured HSC-4 cells were mixed with $1 \times 10^{7}$ normal peripheral blood mononucleocytes (PBMN). PBMN were harvested from the heparinized blood of healthy volunteers using lymphoprep (Axis-Shield PoC AS, Oslo, Norway) gradient centrifugation according to the manufacturer's instructions. The RT product was amplified by PCR with TaqDNA polymerase (Takara Taq, Takara). Primers for SCCA were designed as previously reported (28) (Table I). The outer primers produced a PCR product of $450 \mathrm{bp}$; the inner primers, a PCR product of $307 \mathrm{bp}$. In the first-round PCR for SCCA, the amplication reaction was carried out with initial denaturation at $94^{\circ} \mathrm{C}$ for $5 \mathrm{~min}, 25$ cycles of denaturation at $94^{\circ} \mathrm{C}$ for $1 \mathrm{~min}$, annealing at $45^{\circ} \mathrm{C}$ for $1 \mathrm{~min}$, extension at $72^{\circ} \mathrm{C}$ for $2 \mathrm{~min}$, and final extension at $72^{\circ} \mathrm{C}$ for $7 \mathrm{~min}$. The second-round PCR of 30 cycles had identical reaction parameters except that the annealing temparature was $67^{\circ} \mathrm{C}$. The quality of RNA and cDNA synthesis was ascertained by amplification of glyceraldehydes phosphate dehydrogenase (GAPDH) as the internal control. The primer sequences for GAPDH primers were 5'-GA AATCCCATCACCATCTTCCAGG-3' and 5'-CATGTGGG CCATGAGGTCCACCAC-3'. The following PCR protocol was applied: initial denaturation at $95^{\circ} \mathrm{C}$ for $5 \mathrm{~min}, 30$ cycles of denaturation at $95^{\circ} \mathrm{C}$ for $1 \mathrm{~min}$, annealing at $68^{\circ} \mathrm{C}$ for $1 \mathrm{~min}$, extension at $72^{\circ} \mathrm{C}$ for $2 \mathrm{~min}$, and final extension at $72^{\circ} \mathrm{C}$ for $7 \mathrm{~min}$. PCR products were separated by electrophoresis on a $3 \%$ agarose gel and stained with ethidium bromide.

Detection of distant metastasis. For the evaluation of distant metastasis, pulmonary metastasis was evaluated. Detection of pulmonary metastasis, lung were observed histologically. Dissected specimens were fixed with $10 \%$ formalin and embedded in paraffin. The specimens were sectioned serially at $4 \mu \mathrm{m}$ and stained with hematoxylin and eosin (H\&E).

Statistics. Statistical analysis was performed with SPSS statiscal software (SPSS, Chicago, IL, USA). For comparison of the levels of VEGF mRNA expression in each OSCC cell lines and normal oral epithelial cells, two-way ANOVA was used. Significance of differences was evaluated by using the Bonferroni correction for multiple comparison test in cases where ANOVA was significant. For comparison of MVD of each OSCC cell line transplanted in nude mice, one-way ANOVA was used, when ANOVA showed a significant difference between cell lines, the Bonferroni correction was applied. Comparison of LN metastasis of each OSCC cell line transplanted nude mice was evaluated by using the $\chi^{2}$ test. A P-value of $<0.05$ was considered stastically significant. 
Table III. Two-way analysis of variance.

\begin{tabular}{lrcccc}
\hline Source of variation & Sum of squares & Degrees of freedom & Mean square & F-value & P-value \\
\hline VEGF & 3272102450.9 & 3 & 1090700817.0 & 75.854 & 0.000 \\
VEGF x OSCC cell lines & 664974231.3 & 12 & 55414519.3 & 3.854 & 0.000 \\
Random error (VEGF) & 1164694860.9 & 81 & 14378948.9 & & \\
\hline
\end{tabular}

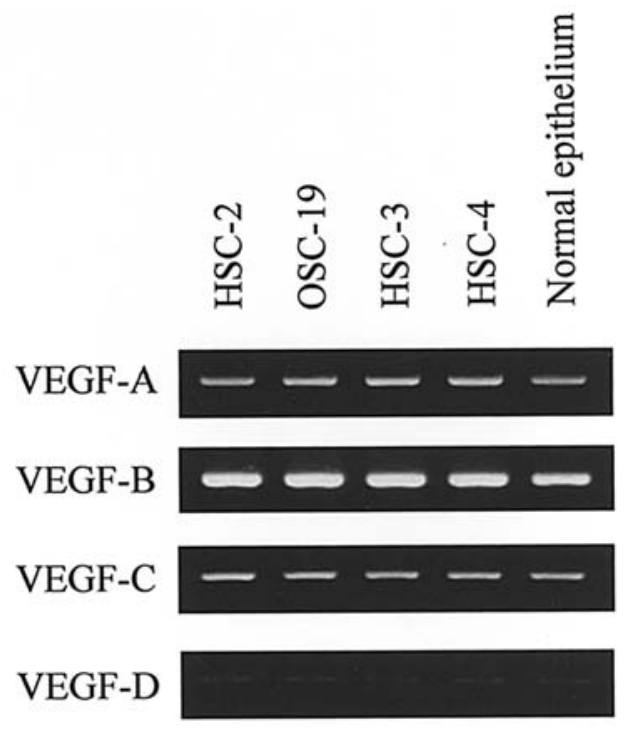

Figure 1. Expression of VEGF-A, -B, -C, and -D mRNA in oral squamous cell carcinoma cell lines and normal oral epithelial cells.

\section{Results}

Expression levels of VEGF MRNA in OSCC cell lines and normal oral epithelial cells. All the VEGF mRNAs were expressed at variable levels in OSCC cell lines and normal oral epithelial cells (Fig. 1). Quantitative real-time PCR analysis revealed that VEGF-C mRNA and VEGF-A mRNA levels in HSC-2 and OSC-19 were significantly higher than the other two VEGF mRNA levels $(\mathrm{P}=0.000)$ (Tables II and III). VEGF-B and VEGF-D mRNA were expressed at lower levels in each OSCC cell line and in normal oral epithelial cells.

Sensitivity and specificity of our detetection of SCCA. Serial dilution experiments showed that the RT-nested PCR assay detected $10^{3}$ HSC-4 cells per $10^{7}$ of PBMN (Fig. 2a). SCCA (a)

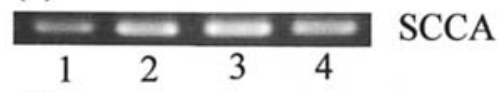

(b)

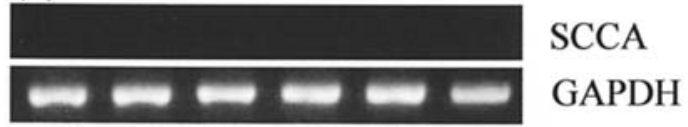

(1) (2) (3) (4) (5) (6)

(c)

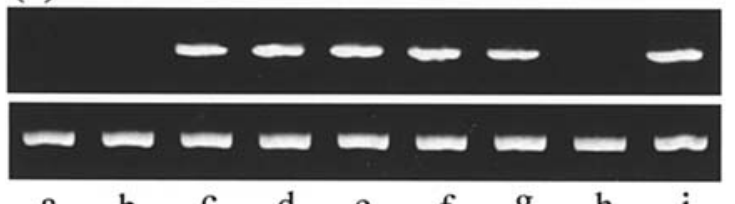

SCCA GAPDH

Figure 2. (a) Expression of SCCA mRNA in OSCC cell lines. SCCA mRNA was detected in all OSCC cell lines. Lane 1, HSC-2; lane 2, HSC-3; lane 3, HSC-4; lane 4, OSC-19. (b) Expression of SCCA mRNA in tongue and lymph nodes of nude mouse without a transplanted tumor. SCCA mRNA was not detected. Lane 1-3, tongue; lane 4-6, lymph nodes. (c) Sensitivity of RT-nested PCR for SCCA mRNA. Serial dilution of HSC-2 cells in normal peripheral blood mononucleocytes (PBMN) was performed to confirm the sensitivity of our assay. Our RT-nested PCR assay detected $10^{3}$ HSC-4 cells per $10^{7}$ of PBMN. Lane a, $10^{1} \mathrm{HSC}-4$ cells $/ 10^{7} \mathrm{PBMN}$; lane b, $10^{2} \mathrm{HSC}-4$ cells $/ 10^{7} \mathrm{PBMN}$; lane c, $10^{3} \mathrm{HSC}-4$ cells $/ 10^{7} \mathrm{PBMN}$; lane d, $10^{4} \mathrm{HSC}-4$ cells $/ 10^{7} \mathrm{PBMN}$; lane e, $10^{5} \mathrm{HSC}-4$ cells $/ 10^{7} \mathrm{PBMN}$; lane f, $10^{6} \mathrm{HSC}-4$ cells $/ 10^{7} \mathrm{PBMN}$; lane g, $10^{7} \mathrm{HSC}-4$ cells $/ 10^{7} \mathrm{PBMN}$; lane h, PBMN; and lane i, HSC-4 cells.

mRNA was detected in all four OSCC cell lines (HSC-2, HSC-3, HSC-4, OSC-19) (Fig. 2b). We did not detect SCCA mRNA in tongue or LN of mice without a transplanted tumor (Fig. 2c).

Clinicopathological factors in tumor transplanted nude mice. Table IV shows the clinicopathological factors in tumor transplanted mice. MVD of HSC-2 and OSC-19 were also
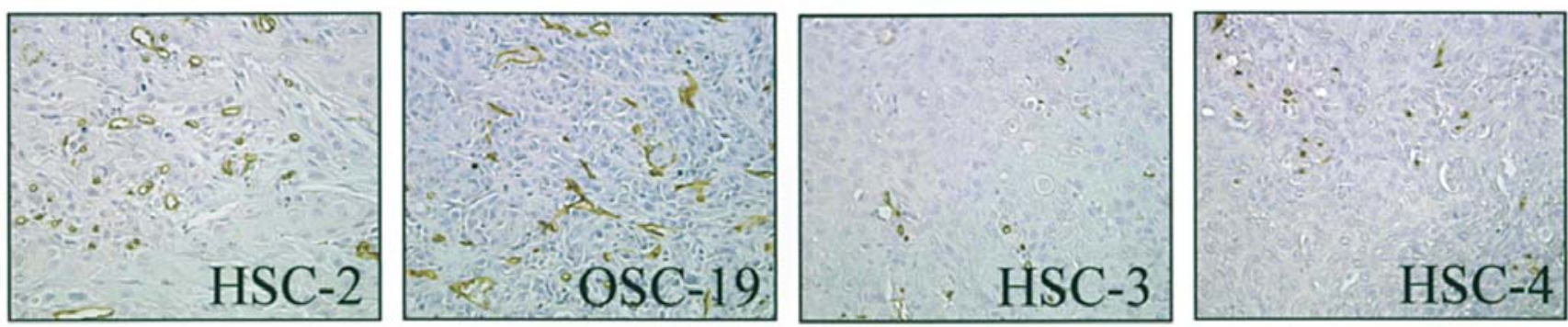

Figure 3. Microvessels were identified by immunohistochemical staining against CD34. To determine microvessel density, three fields with high vascularity were selected. Microvessels were counted under a light microscope at x400 magnification and the results are expressed as the number of vessels per field. 
Table IV. Clinicopathological factors in vivo.

\begin{tabular}{lccc}
\hline & MVD & $\begin{array}{c}\text { LN } \\
\text { metastasis (\%) }\end{array}$ & $\begin{array}{c}\text { Pulmonary } \\
\text { metastasis (\%) }\end{array}$ \\
\hline HSC-2 & $22.95 \pm 0.88$ & 64.3 & 0 \\
OSC-19 & $22.27 \pm 1.42$ & 66.7 & 0 \\
HSC-3 & $10.95 \pm 1.06$ & 14.3 & 0 \\
HSC-4 & $14.08 \pm 1.83$ & 31.3 & 0 \\
\hline
\end{tabular}

significantly higher than those of HSC-3 and HSC-4 $(\mathrm{P}=0.000)$ (Fig. 3). Also, LN metastasis-positive cases were significantly higher in HSC-2 and OSC-19 than in HSC-3 and HSC-4 $(\mathrm{P}=0.007)$. Pulmonary metastasis was not found in any of the mice.

\section{Discussion}

In the present study, we investigated whether the expression of the VEGFs, VEGF-A, VEGF-B, VEGF-C and VEGF-D in OSCC cell lines correlated with clinicopathological factors in tumor transplanted nude mice. Our main hypothesis was that the expression patterns of VEGFs would be different for each OSCC, and that these differences would be associated with the metastatic potential. HSC-2 and OSC-19, which expressed higher levels of VEGF-C and VEGF-A, caused frequent LN metastasis and high MVD in nude mice. VEGF-C is a lymphangiogenic factor and VEGF-A is an angiogenic factor. Considering these points, our results suggest that the expression levels of VEGF-C and VEGF-A correlate with, respectively, lymphatic metastasis and angiogenesis. This relationship is consistent with previous studies that showed positive correlation of VEGF-C levels and LN metastasis $(7,8,19,20)$. Sedivy et al for example, reported that the expression of VEGF-C correlates with lymphatic microvessel density and nodal status in OSCC (20). While the expression of VEGF-A that correlated to distant metastasis in addition to MVD was expected, there was no correlation between VEGF-A expression and distant metastasis in our study. To prevent cruelty to animals, observation periods were set at 3 weeks to minimize the influence of tumor transplantation on the feeding of mice, but this observation period may have been too short to establish distant metastasis.

On the basis of our present study, VEGF-C expression is highly related to LN metastasis. Since LN metastasis is the most important prognostic factor in OSCC, identification of better markers that would identify patients with biologically aggressive tumors would provide a much needed opportunity to target patients at risk of developing metastasis. VEGF-C expression appears to be a novel predictive factor for $\mathrm{LN}$ metastasis.

\section{Acknowledgements}

We thank Dr M. Nagata (Division of Oral and Maxillofacial Surgery, Niigata University Graduate School of Medical and
Dental Sciences) for his valuable suggestions regarding the quantitative RT-PCR assay and Professor E. Yamamoto (Department of Oral and Maxillofacial Surgery, Kanazawa University) for his kind gift of OSC-19 cells.

\section{References}

1. Folkman J: Angiogenesis in cancer, vascular, rheumatoid and other disease. Nat Med 1: 27-31, 1995.

2. Shweiki D, Neeman M, Itin A and Keshet E: Induction of vascular endothelial growth factor expression by hypoxia and by glucose deficiency in multicell spheroids: implications for tumor angiogenesis. Proc Natl Acad Sci USA 92: 768-772, 1995.

3. Li $\mathrm{X}$ and Eriksson U: Novel VEGF family members: VEGF-B, VEGF-C and VEGF-D. Int J Biochem Cell Biol 33: 421-426, 2001.

4. Olofsson B, Pajusola K, Kaipainen A, von Euler G, Joukov V, Saksela O, Orpana A, Pettersson RF, Alitalo K and Eriksson U: Vascular endothelial growth factor B, a novel growth factor for endothelial cells. Proc Natl Acad Sci USA 93: 2576-2581, 1996.

5. Joukov V, Pajusola K, Kaipainen A, Chilov D, Lahtinen I, Kukk E, Saksela O, Kalkkinen N and Alitalo K: A novel vascular endothelial growth factor, VEGF-C, is a ligand for the Flt4 (VEGFR-3) and KDR (VEGFR-2) receptor tyrosine kinases. EMBO J 15: 290-298, 1996.

6. Achen MG, Jeltsch M, Kukk E, Makinen T, Vitali A, Wilks AF, Alitalo K and Stacker SA: Vascular endothelial growth factor D (VEGF-D) is a ligand for the tyrosine kinases VEGF receptor 2 (Flk1) and VEGF receptor 3 (Flt4). Proc Natl Acad Sci USA 95: 548-553, 1998.

7. O-Charoenrat P, Rhys-Evans $\mathrm{P}$ and Eccles SA: Expression of vascular endothelial growth factor family members in head and neck squamous cell carcinoma correlates with lymph node metastasis. Cancer 92: 556-568, 2001.

8. Shintani S, Li C, Ishikawa T, Mihara M, Nakashiro K and Hamakawa $\mathrm{H}$ : Expression of vascular endothelial growth factor A, B, C, and D in oral squamous cell carcinoma. Oral Oncol 40: $13-20,2004$.

9. Niki T, Iba S, Tokunou M, Yamada T, Matsuno Y and Hirohashi S: Expression of vascular endothelial growth factors $\mathrm{A}, \mathrm{B}, \mathrm{C}$, and $\mathrm{D}$ and their relationships to lymph node status in lung adenocarcinoma. Clin Cancer Res 6: 2431-2439, 2000.

10. Ellis LM and Fidler IJ: Angiogenesis and metastasis. Eur J Cancer 32A: 2451-2460, 1996.

11. Smith BD, Smith GL, Carter D, Sasaki CT and Haffty BG: Prognostic significance of vascular endothelial growth factor protein levels in oral and oropharyngeal squamous cell carcinoma. J Clin Oncol 18: 2046-2052, 2000.

12. Mineta H, Miura K, Ogino T, Takebayashi S, Misawa K, Ueda Y, Suzuki I, Dictor M, Borg A and Wennerberg J: Prognostic value of vascular endothelial growth factor (VEGF) in head and neck squamous cell carcinomas. Br J Cancer 83: 775-781, 2000.

13. Uehara M, Sano K, Ikeda H, Sekine J, Irie A, Yokota T, Tobita T, Ohba $S$ and Inokuchi T: Expression of vascular endothelial growth factor and prognosis of oral squamous cell carcinoma. Oral Oncol 40: 321-325, 2004.

14. Wong YK, Liu CJ, Kwan PC and Chao SY: Microvascular density and vascular endothelial growth factor immunoreactivity as predictors of regional lymph node metastasis from betelassociated oral squamous cell carcinoma. J Oral Maxillofac Surg 61: 1257-1262, 2003.

15. Joukov V, Sorsa T, Kumar V, Jeltsch M, Claesson-Welsh L, Cao Y, Saksela O, Kalkkinen N and Alitalo K: Proteolytic processing regulates receptor specificity and activity of VEGF-C. EMBO J 16: 3898-3911, 1997.

16. Kukk E, Lymboussaki A, Taira S, Kaipainen A, Jeltsch M, Joukov $\mathrm{V}$ and Alitalo K: VEGF-C receptor binding and pattern of expression with VEGFR-3 suggests a role in lymphatic vascular development. Development 122: 3829-3837, 1996.

17. Jeltsch M, Kaipainen A, Joukov V, Meng X, Lakso M, Rauvala H, Swartz M, Fukumura D, Jain RK and Alitalo K: Hyperplasia of lymphatic vessels in VEGF-C transgenic mice. Science 276 : 1423-1425, 1997.

18. Yonemura Y, Endo Y, Fujita H, Fushida S, Ninomiya I, Bandou E, Taniguchi K, Miwa K, Ohoyama S, Sugiyama K and Sasaki T: Role of vascular endothelial growth factor C expression in the development of lymph node metastasis in gastric cancer. Clin Cancer Res 5: 1823-1829, 1999. 
19. Kishimoto K, Sasaki A, Yoshihama Y, Mese H, Tsukamoto G and Matsumura T: Expression of vascular endothelial growth factor-C predicts regional lymph node metastasis in early oral squamous cell carcinoma. Oral Oncol 39: 391-396, 2003.

20. Sedivy R, Beck-Mannagetta J, Haverkampf C, Battistutti W and Honigschnabl S: Expression of vascular endothelial growth factor-C correlates with the lymphatic microvessel density and the nodal status in oral squamous cell cancer. J Oral Pathol Med 32: 455-460, 2003.

21. Olofsson B, Korpelainen E, Pepper MS, Mandriota SJ, Aase K, Kumar V, Gunji Y, Jeltsch MM, Shibuya M, Alitalo K and Eriksson U: Vascular endothelial growth factor B (VEGF-B) binds to VEGF receptor-1 and regulates plasminogen activator activity in endothelial cells. Proc Natl Acad Sci USA 95: 11709-11714, 1998.

22. Marconcini L, Marchio S, Morbidelli L, Cartocci E, Albini A, Ziche M, Bussolino F and Oliviero S: c-fos-induced growth factor/ vascular endothelial growth factor $\mathrm{D}$ induces angiogenesis in vivo and in vitro. Proc Natl Acad Sci USA 96: 9671-9676, 1999.

23. Momose F, Araida T, Negishi A, Ichijo H, Shioda S and Sasaki S: Variant sublines with different metastatic potentials selected in nude mice from human oral squamous cell carcinomas. J Oral Pathol Med 18: 391-395, 1989.

24. Kawashiri S, Kumagai S, Kojima K, Harada H and Yamamoto E: Development of a new invasion and metastasis model of human oral squamous cell carcinomas. Eur J Cancer B Oral Oncol 31: 216-221, 1995.

25. Yoshizawa M, Feinberg SE, Marcelo CL and Elner VM: Ex vivo produced human conjunctiva and oral mucosa equivalents grown in a serum-free culture system. J Oral Maxillofac Surg 62: $980-988,2004$
26. De Bruijn HW, Duk JM, van der Zee AG, Pras E, Willemse PH, Boonstra H, Hollema H, Mourits MJ, de Vries EG and Aalders JG: The clinical value of squamous cell carcinoma antigen in cancer of the uterine cervix. Tumour Biol 19: 505-516, 1998.

27. Fischbach W, Meyer T and Barthel K: Squamous cell carcinoma antigen in the diagnosis and treatment follow-up of oral and facial squamous cell carcinoma. Cancer 65: 1321-1324, 1990.

28. Stenman J, Lintula S, Hotakainen K, Vartiainen J, Lehvaslaiho H and Stenman UH: Detection of squamous-cell carcinoma antigen-expressing tumour cells in blood by reverse transcriptasepolymerase chain reaction in cancer of the uterine cervix. Int $\mathbf{J}$ Cancer 74: 75-80, 1997.

29. Hamakawa H, Fukizumi M, Bao Y, Sumida T, Onishi A, Tanioka H, Sato H and Yumoto E: Genetic diagnosis of micrometastasis based on SCC antigen mRNA in cervical lymph nodes of head and neck cancer. Clin Exp Metastasis 17: 593-599, 1999.

30. Kano M, Shimada Y, Kaganoi J, Sakurai T, Li Z, Sato F, Watanabe $G$ and Imamura M: Detection of lymph node metastasis of oesophageal cancer by RT-nested PCR for SCC antigen gene mRNA. Br J Cancer 82: 429-435, 2000.

31. Onishi A, Nakashiro K, Mihara M, Sumida T, Kawamata H, Shintani S, Aida T, Tachikawa T and Hamakawa H: Basic and clinical studies on quantitative analysis of lymph node micrometastasis in oral cancer. Oncol Rep 11: 33-39, 2004. 